\title{
Involvement of deprivation and environmental lead in neural tube defects: a matched case-control study
}

\author{
John P Bound, Peter W Harvey, Brian J Francis, Fuad Awwad, Anthony C Gatrell
}

\begin{abstract}
Objective-To analyse the prevalence of neural tube defects in small geographical areas and seek to explain any spatial variations with reference to environmental lead and deprivation.

Setting-The Fylde of Lancashire in the north west of England.

Design-Cases were ascertained as part of a prospective survey of major congenital malformations in babies born in the Fylde to residents there between 1957 and 1981 . A matched case-control analysis used infants with cardiovascular system, alimentary tract, and urinary system malformations as controls. Conditional logistic regression was used to assess the effects of more than $10 \mu \mathrm{g} / 1$ lead in drinking water and the Townsend deprivation score.

Results-The prevalence of neural tube defects in 1957-73 was higher in Blackpool, Fleetwood, and North Fylde, whereas the three control groups showed no significant spatial variation. In 1957-81 mothers living in electoral wards with either a higher proportion of houses with more than $10 \mu \mathrm{g} / 1$ lead in the water or a higher deprivation score had a greater risk of having a baby with a neural tube defect. For spina bifida and cranium bifidum alone, this was also true. For anencephaly, deprivation was less important although the effect of lead was still seen. In some neural tube defects, lead may act independently of other possible factors associated with deprivation. It seemed unlikely that lead levels changed significantly during the survey. The percentage of houses with $10 \mu \mathrm{g} / 1$ or more of lead in the water in 1984-5 was similar to that found in Great Britain 10 years previously. Conclusion-There is evidence to suggest that lead is one cause of neural tube defects, especially anencephaly. This could link the known preventive actions of hard water and folic acid. Calcium is a toxicological antagonist of lead. One cause of a deficiency of folic acid is impaired absorption secondary to zinc deficiency, which may be produced or exacerbated by lead.
\end{abstract}

(Arch Dis Child 1997;76:107-112)

Dr Bound.

Accepted 1 October 1996

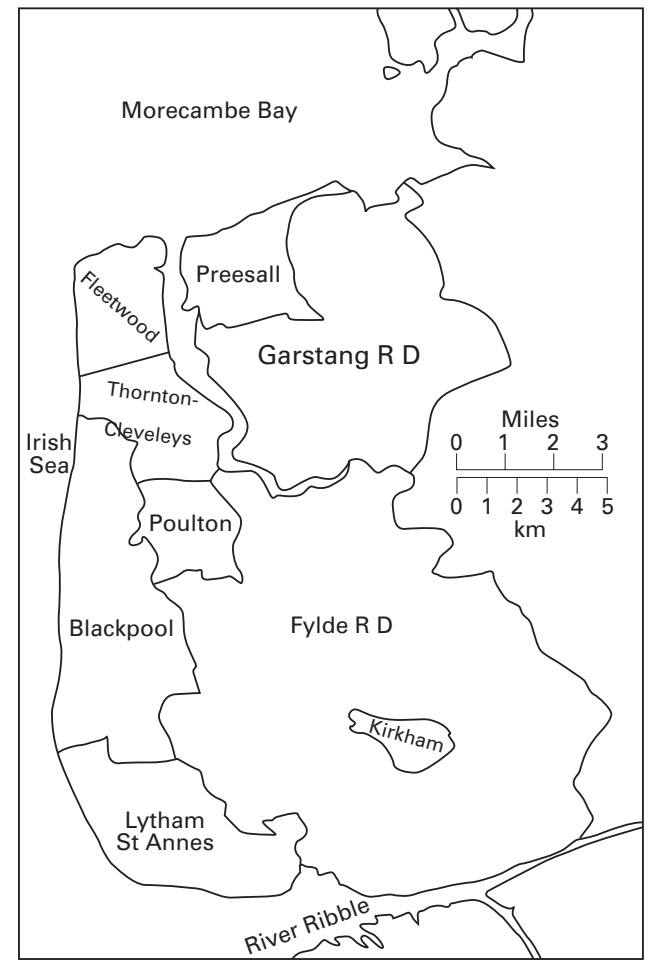

Figure 1 The Fylde of Lancashire.

This paper presents the results of a small geographical area analysis of the prevalence of neural tube defects in the Fylde of Lancashire (fig 1). Explanations for spatial variations are sought, particularly an association with environmental lead.

North west England, of which the Fylde is a part, is known to have been an area of high prevalence of central nervous system malformations, ${ }^{1}$ as have other areas, such as south Wales in which considerable local variation was found. ${ }^{2}$ In the Fylde between 1956 and 1967 a north-south gradient in the prevalence of anencephaly was demonstrated. ${ }^{3}$ This feature disappeared after 1967 when there was a sudden fall in the prevalence of anencephaly to below the national average. ${ }^{4}$

Water quality has long been associated in the results of some investigations with geographical variation in the prevalence of neural tube defects. In south Wales the prevalence at birth of malformations of the central nervous system was negatively correlated with hardness of local water supplies. ${ }^{5}$ It was thought that a causal water factor was unlikely as confounding by 
socioeconomic conditions could not be excluded.

In a study in south west Lancashire it was concluded that it was unlikely that the nature of the local water supply played any short term part in the pathogenesis of anencephaly. ${ }^{6}$

A case-control study, also in south Wales, found no convincing evidence of an association between neural tube malformations and the trace element content of tap water, although there was a small deficit in zinc for the cases. ${ }^{7}$

An investigation in the Fylde, ${ }^{4}$ which had its own water supply, provided strong evidence that hard water could exercise a protective effect against anencephaly. The water was soft until the 1960s when increasing hardness of the summer water was associated with a significant fall in prevalence of anencephaly not seen elsewhere in the north west region.

An environmental factor that could cause small area variations in prevalence of neural tube defects must depend on socioeconomic conditions. A link between deprivation and water quality could be provided by the neurotoxin lead. Poorer districts tend to have older houses more likely to contain lead pipes, which may raise lead levels in the drinking water.

High concentrations of lead and cadmium have been found in the bones of stillborn babies, many of which were malformed. ${ }^{8}$

\section{Methods}

The cases in this study were ascertained in a prospective survey of major congenital malformations in babies born to mothers resident in the Fylde during the period 1957-81, and described elsewhere. ${ }^{9}$

The consultant obstetric unit and the children's department of Blackpool Victoria Hospital served all of the Fylde, and thus ascertainment of cases by one consultant paediatrician during his daily clinical practice was facilitated. A very high rate of necropsies was maintained throughout the survey period. Terminations of pregnancy after antenatal diagnosis of neural tube defects were ascertained from the local obstetricians' records. The number of live and stillbirths was obtained annually from the medical officers of health until 1973 and thereafter from the Office of Population Censuses and Surveys.

There were 88449 births in the 25 years, from a population which increased from about 250000 to over 300000 . There were 364 cases of neural tube defects, comprising 169 anencephaly and 195 spina bifida and cranium bifidum. The majority (70\%) were born between 1957 and 1968.

Data collected on each case included date of birth, age, and parity of the mother, month and year of the last menstrual period (LMP), the sex and birth weight of the baby, and a ward code, classifying the area of residence of the mother in the first three months of pregnancy to one of the 64 electoral wards as they existed in 1971 .

In the absence of suitable control data on births of normal babies disaggregated by electoral wards, the suggestion was adopted that a group of mothers who have delivered infants with other malformations may be the control group of choice in epidemiological studies of neural tube defects. ${ }^{10}$ Adequate numbers with complete data in certain other malformation groups had been collected over the same period as the cases. Three control groups of babies were therefore used: (a) cardiovascular malformations, excluding those with neural tube defects or Down's syndrome (531 cases); (b) alimentary tract malformations, excluding those with neural tube defects, Down's syndrome, or cardiovascular malformations (156 cases); (c) urinary tract malformations, excluding those with neural tube defects, Down's syndrome, cardiovascular malformations, and alimentary tract malformations (205 cases). The malformations included in these categories were detailed previously. ${ }^{9}$ In subsequent analysis, the urinary tract malformations were combined with the alimentary tract malformations to provide a second workable set of controls.

In interpreting the results of a study using such control groups, the assumption is that the control groups are unaffected by local environmental variables and therefore their underlying prevalence rate in each ward or district will be similar. A random spatial distribution of cardiovascular malformations in the Fylde had been suggested previously. ${ }^{11}$

Lead concentrations in drinking water measured in $\mu \mathrm{g} / 1$ were provided by the Fylde Water Board until 1974 and then by North West Water. Chemical analyses were made regularly during 1957-81 on samples from two taps in Blackpool, which represented the mains supplies to the whole area. There was no extensive random survey of lead levels from domestic premises until 1984-5. This consisted of 1076 random unflushed daytime samples from kitchen taps, together with the ward within which the premises was situated. In our analyses, we have used $10 \mu \mathrm{g} / \mathrm{l}$ lead as the maximum admissible concentration in drinking water. This follows the WHO recommendation ${ }^{12}$ and the proposal of the European Commission ${ }^{13}$ that this is the maximum value that could be supported without compromising the health of infants and pregnant women. The proportion of surveyed households in each ward with lead concentrations greater than this maximum was then calculated. This ranged from $94 \%$ in Warren ward in Fleetwood to $0 \%$ in certain wards in North and South Fylde.

As previous work ${ }^{14}$ had found an association between the prevalence of neural tube defects and the proportion of semi and unskilled workers of social classes IV and V, socioeconomic data were also sought. Individual data on the social and economic background of each mother were not available. Data from the 1971 census were therefore used to calculate the Townsend deprivation score ${ }^{15}$ for each ward. This is calculated from four census variables: (a) unemployment - that is, the percentage of economically active residents who are unemployed; (b) car ownership - that is, the percentage of private households who do not possess a car; (c) housing tenure-that is, 
Table 1 Initial analysis of the yearly prevalence of each congenital abnormality group for 1957-73

\begin{tabular}{|c|c|c|c|c|c|}
\hline Model & Deviance & $d f$ & Difference in deviance & $d f$ & $p$ Value \\
\hline \multicolumn{6}{|l|}{ Anencephaly } \\
\hline Constant prevalence & 110.82 & 67 & - & - & - \\
\hline + Year of birth & 88.839 & 66 & 21.98 & 1 & 0.001 \\
\hline+ District & 67.955 & 63 & 20.88 & 3 & 0.001 \\
\hline + Interaction & 64.747 & 60 & 3.208 & 3 & 0.361 \\
\hline \multicolumn{6}{|l|}{$\begin{array}{l}\text { Spina bifida and cranium } \\
\text { bifidum }\end{array}$} \\
\hline Constant prevalence & 70.914 & 67 & - & - & - \\
\hline + Year of birth & 63.843 & 66 & 7.071 & 1 & 0.007 \\
\hline+ District & 55.193 & 63 & 8.650 & 3 & 0.034 \\
\hline + Interaction & 54.938 & 60 & 0.255 & 3 & 0.968 \\
\hline \multicolumn{6}{|l|}{ Cardiovascular } \\
\hline Constant prevalence & 83.093 & 67 & - & - & - \\
\hline + Year of birth & 82.752 & 66 & 0.342 & 1 & 0.558 \\
\hline + District & 76.430 & 63 & 6.322 & 3 & 0.096 \\
\hline+ Interaction & 74.400 & 60 & 2.030 & 3 & 0.566 \\
\hline \multicolumn{6}{|c|}{ Urinary tract malformations } \\
\hline Constant prevalence & 80.953 & 67 & - & - & - \\
\hline+ Year of birth & 74.179 & 66 & 6.774 & 1 & 0.009 \\
\hline + District & 69.660 & 63 & 4.519 & 3 & 0.211 \\
\hline+ Interaction & 68.326 & 60 & 1.334 & 3 & 0.721 \\
\hline \multicolumn{6}{|c|}{ Alimentary tract malformations } \\
\hline Constant prevalence & 72.635 & 67 & - & - & - \\
\hline + Year of birth & 72.276 & 66 & 0.358 & 1 & 0.549 \\
\hline + District & 70.788 & 63 & 1.488 & 3 & 0.685 \\
\hline+ Interaction & 69.771 & 60 & 1.016 & 3 & 0.797 \\
\hline
\end{tabular}

$\mathrm{df}=$ degrees of freedom.

Table 2 Prevalence of neural tube defects per 1000 births in each district (number of cases in parentheses)

\begin{tabular}{llllll}
\hline & Blackpool & Fleetwood & North Fylde & South Fylde & Total \\
\hline Anencephaly & & & & & \\
$\quad 1957-61$ & $3.3(30)$ & $4.6(12)$ & $3.7(10)$ & $1.8(7)$ & $3.2(59)$ \\
$\quad 1962-6$ & $3.2(33)$ & $2.7(7)$ & $3.2(11)$ & $0.4(2)$ & $2.5(53)$ \\
$\quad 1967-73$ & $1.8(22)$ & $1.0(3)$ & $1.5(7)$ & $0.5(3)$ & $1.4(35)$ \\
Total & $2.7(85)$ & $2.7(22)$ & $2.6(28)$ & $0.8(12)$ & $2.3(147)$ \\
Spina bifida and cranium & & & & & \\
$\quad$ bifidum & & & & \\
$\quad 1957-61$ & $3.3(30)$ & $3.5(9)$ & $3.0(8)$ & $2.3(9)$ & $3.1(56)$ \\
$\quad 1962-6$ & $3.1(32)$ & $5.5(14)$ & $1.4(5)$ & $1.5(7)$ & $2.8(58)$ \\
$\quad 1967-73$ & $2.5(30)$ & $2.0(6)$ & $2.3(11)$ & $1.4(8)$ & $2.1(55)$ \\
Total & $2.9(92)$ & $3.5(29)$ & $2.2(24)$ & $1.7(24)$ & $2.6(169)$ \\
\hline
\end{tabular}

the percentage of private households not owner occupied; (d) household overcrowding - that is, the percentage of private households with more than one person per room.

Following Townsend's methodology, the unemployment and overcrowding variables were $\log$ transformed to approximate normality. $Z$ scores were then calculated for each variable, and summed to produce a deprivation score for each ward. The most deprived wards were Park in Fleetwood and Bank Hey in Blackpool with scores of 5.779 and 5.025 respectively; the least deprived were Ribby with Wrea in South Fylde and High Cross in North Fylde with scores of -5.639 and -5.339 respectively.

The statistical analysis of the data was carried out using GLIM, ${ }^{16}$ and consisted of two stages. The first stage consisted of an initial analysis of the yearly prevalence rate of each case and control malformation group using logistic regression, with year of birth and district of residence as covariates. This analysis, which investigated the temporal and spatial variation in the rates, was carried out on malformations born between 1957 and 1973, as total births disaggregated by district are known only for that period. The cases were grouped into four districts: Fleetwood, Blackpool, North Fylde (combining Thornton-
Cleveleys, Poulton, Preesall, and Garstang $\mathrm{RD}$ ), and South Fylde (combining Lytham St Annes, Kirkham, and Fylde RD). These comprise the three administrative districts of the area but with the port of Fleetwood, thought to have a high malformation rate, considered separately from the rest of North Fylde.

The second stage was a matched casecontrol analysis, examining the effect of lead levels and deprivation on the relative risk of a neural tube defect birth compared with a control malformation birth during 1957-81. Matching of controls to cases was carried out by allowing a match if the date of LMP of the control was within plus or minus one month of the date of LMP of the case. This produced multiple and varying numbers of controls matched with each case. Conditional logistic regression was used to assess the effects of lead (as assessed by the proportion of households with high lead levels in each ward) and ward deprivation score, controlling additionally for the age of the mother, the parity of the mother, and the sex of the baby.

In the results of these analyses (tables 1 and 4) the change in the deviance measures the increase in the goodness of fit as each explanatory variable is added to the model. The changes in deviance can be regarded as $\chi^{2}$ with the appropriate number of degrees of freedom.

\section{Results}

The initial analysis of the yearly prevalence rate of each of the malformation groups yielded the results shown in table 1 . For the control malformation groups of cardiovascular system malformations and alimentary tract malformations, there was no evidence of variation in prevalence rate either over time or between districts. For the third control group (urinary tract malformations) there was evidence of an increase in prevalence rate over time. This is due to increasing recognition of vesicoureteric reflux during the first 10 years of the study period. Analysis of neural tube defects showed evidence of significant variation between districts and over time for both anencephaly and spina bifida. This can be observed in table 2, which shows the observed prevalence rates per 1000 births for each malformation group. The prevalence of anencephaly was lower in South Fylde, and the decline over time in all four districts can be observed. Fleetwood had the highest prevalence rate for spina bifida and cranium bifidum and South Fylde the lowest; a less marked decline over time can also be seen. No malformation group had a significant time by district interaction; there was therefore no evidence that the temporal effects for anencephaly and urinary tract malformations were different across districts.

This analysis provides evidence that the prevalence of neural tube defects varies across districts, and that therefore the search for some environmental associative factor is reasonable. The analysis of the control group malformations shows no such spatial variation, confirming that they are therefore suitable control groups to use in subsequent analysis. The increase in prevalence rates noted for urinary 
Table 3 Number of matched and unmatched cases for each case-control group combination in 1975-81

\begin{tabular}{lllll}
\hline Case group & Control group & $\begin{array}{l}\text { No of matched } \\
\text { cases }\end{array}$ & $\begin{array}{l}\text { No of unmatched } \\
\text { cases }\end{array}$ & $\begin{array}{l}\text { No of matched } \\
\text { controls }\end{array}$ \\
\hline Anencephaly & Cardiovascular & 158 & 11 & 469 \\
Anencephaly & Alimentary and urinary & 142 & 27 & 218 \\
Anencephaly & Combined & 163 & 6 & 499 \\
Spina bifida and cranium bifidum & Cardiovascular & 183 & 12 & 404 \\
Spina bifida and cranium bifidum & Alimentary and urinary & 171 & 24 & 299 \\
Spina bifida and cranium bifidum & Combined & 194 & 1 & 830 \\
All neural tube defects & Combined & 348 & 16 & 806 \\
\hline
\end{tabular}

Table 4 Results of matched case-control analyses using combined control group in 1957-81

\begin{tabular}{|c|c|c|c|c|c|c|c|c|}
\hline Model & Deviance & $d f$ & Effect & $\begin{array}{l}\text { Difference in } \\
\text { deviance }\end{array}$ & $d f$ & $p$ Value & $\begin{array}{l}\text { Estimate of } \\
\text { effect }\end{array}$ & $S E$ \\
\hline \multicolumn{9}{|l|}{ Anencephaly } \\
\hline Base & 397.42 & 494 & - & - & - & - & - & - \\
\hline Base + lead & 390.76 & 493 & Lead & 6.66 & 1 & 0.010 & 1.175 & 0.460 \\
\hline Base + deprivation & 394.45 & 493 & Deprivation & 2.97 & 1 & 0.085 & 0.056 & 0.033 \\
\hline $\begin{array}{r}\text { Base }+ \text { lead }+ \\
\text { deprivation }\end{array}$ & 390.64 & 492 & $\begin{array}{l}\text { Lead controlling for } \\
\text { deprivation }\end{array}$ & 3.81 & 1 & 0.051 & 1.069 & 0.552 \\
\hline \multicolumn{9}{|c|}{$\begin{array}{l}\text { Spina bifida and cranium } \\
\text { bifidum }\end{array}$} \\
\hline Base & 532.66 & 704 & - & - & 一 & - & - & - \\
\hline Base + lead & 526.78 & 703 & Lead & 5.88 & 1 & 0.015 & 0.960 & 0.397 \\
\hline Base + deprivation & 528.60 & 703 & Deprivation & 4.06 & 1 & 0.044 & 0.059 & 0.029 \\
\hline $\begin{array}{c}\text { Base }+ \text { lead }+ \\
\text { deprivation }\end{array}$ & 526.04 & 702 & $\begin{array}{l}\text { Lead controlling for } \\
\text { deprivation }\end{array}$ & 2.56 & 1 & 0.110 & 0.747 & 0.467 \\
\hline \multicolumn{9}{|l|}{ All neural tube defects } \\
\hline Base & 719.22 & 787 & - & - & - & - & - & - \\
\hline Base + lead & 711.14 & 786 & Lead & 8.08 & 1 & 0.004 & 0.901 & 0.318 \\
\hline Base + deprivation & 712.37 & 786 & Deprivation & 6.85 & 1 & 0.009 & 0.065 & 0.025 \\
\hline $\begin{array}{r}\text { Base }+ \text { lead }+ \\
\text { deprivation }\end{array}$ & 709.28 & 785 & $\begin{array}{l}\text { Lead controlling for } \\
\text { deprivation }\end{array}$ & 3.09 & 1 & 0.079 & 0.647 & 0.368 \\
\hline
\end{tabular}

tract malformations causes no problem, as cases are matched to controls according to date of LMP, and temporal variation is thus suitably controlled for.

Matching of controls to cases was then carried out. Anencephaly cases were matched firstly to the cardiovascular controls, secondly to the alimentary and urinary tract controls, and lastly to a combined control group. A similar exercise was carried out for spina bifida and cranium bifidum cases. Neural tube defect cases were matched to only the combined control group, as using the individual control groups resulted in too few cases being matched. This yielded seven separate matched sets, with a variable number of controls matched to each case. Table 3 shows the results of the matching. In each matched set the number of unmatched cases is small.

Conditional logistic regression analysis ${ }^{17}$ was carried out on each of the seven matched sets. Each analysis controlled for sex of the child, and age and parity of the mother, and these three variables defined a 'base' model. The lead and deprivation variables were then added to this base model, first separately, then together. Changes in deviance thus produced allowed the effects of lead alone, deprivation alone, and lead controlling for deprivation to be assessed.

Initial results using the cardiovascular and the alimentary and urinary controls separately gave similar results, and provided validity for using the combined controls as a single control group. The results of the analyses using the combined control group for each malformation category are shown in table 4 . Lead considered alone gives significantly raised odds of a neural tube defect over a control malformation in all analyses. Deprivation considered alone is significant for all neural tube defects and for spina bifida and cranium bifidum, but lead alone explains more variation in the data than the effect of deprivation alone in both these malformation categories. Finally, the effect of lead controlling for deprivation score just fails to reach conventional levels of significance for anencephaly, but is not significant for spina bifida and cranium bifidum or for all neural tube defects.

The parameter estimates given in table 4 are estimated changes in log odds ratios of a case malformation against a control malformation related to a unit change in the explanatory variable. Under the assumption of no spatial variation in the control malformations, we can interpret this as a relative risk of a case malformation compared with a normal birth. The parameter estimate for lead alone is close to 1 for all three malformation categories, suggesting that the relative risk of a neural tube malformation compared with a normal birth increases by $0.1 \times \exp (1)$ which is about $25 \%$ for each $10 \%$ increase in the number of houses with tap water lead levels greater than $10 \mu \mathrm{g} / \mathrm{l}$.

\section{Discussion}

We have shown that mothers living in wards where the proportion of houses with more than $10 \mu \mathrm{g} / 1$ lead in their water is higher have a greater risk of having a baby with a neural tube defect.

During the period of high prevalence of neural tube defects, mains water was lead-free and the $\mathrm{pH}$ was kept in the range $7-9$, whether the water was soft or slightly harder, obviating increased plumbosolvency from acidity. Lead in domestic water originated from pipes or a lined tank in the house. It must be noted that the first survey of lead in random domestic samples from the whole Fylde was carried out 
three years after our study of neural tube defects ended. This raises the possibility of a significant change in the percentage of houses with raised lead levels since the mid-1960s, resulting from the use of non-lead pipes in either new building or modernisation of plumbing in existing houses. Most houses built before 1964 have some lead pipework ${ }^{18}$ but its use was prohibited from 1976. However, lead solder, which can produce high levels at the tap, was not banned. ${ }^{19}$

Replacement of lead pipes from the boundary of the property is the responsibility of householders and therefore occurred only when they considered it necessary. As recently as the 1980s, a Royal Commission on Environmental Pollution made recommendations to increase pipe replacement which were largely ignored. ${ }^{19}$

A survey in 1975 initiated by the Department of the Environment found $35.5 \%$ of households in Great Britain with lead levels of $10 \mu \mathrm{g} / 1$ or more and $10.3 \%$ with $50 \mu \mathrm{g} / 1$ or more. $^{20}$ The corresponding figures for the Fylde 10 years later in 1984-5 were 39.6 and $10.5 \%$. Thus there is no reason to believe the modernisation of plumbing or new building have influenced our results significantly.

In addition to water, dust contaminated by leaded petrol exhaust emissions or industrial processes may be a source of lead exposure. It was considered that petrol might be relevant in central Blackpool where traffic is heavy, particularly in the two month autumn 'illuminations' period. However, a study of mean isotopic ratios of lead in deciduous teeth shed by children in the Fylde in the latter half of $1991^{21}$ showed that the types of lead in teeth obtained in Blackpool reflected those found in drinking water. This does not completely rule out some association with dust at the time when neural tube defects were commoner, which predated the availability of lead-free petrol.

We have also shown that mothers living in wards with a high deprivation score are at greater risk of having a baby with a neural tube defect. This association could result from one or more factors, for example dietary deficiency, old or poor housing, infections or environmental pollution. Low income families tend to live in older houses which are more likely to contain lead pipes. Thus lead in the water may simply be another indicator of deprivation. However, for anencephaly, deprivation considered alone was not significant although lead was. Indeed, the effect of lead approaches significance even when deprivation is controlled for. This finding was supported by an earlier paper ${ }^{4}$ showing the preventive action of hard water against anencephaly. Calcium and magnesium are toxicological antagonists of lead.

Further evidence that lead is causal in impaired fetal development came from a study of placentas, including some from Blackpool. ${ }^{22}$ There was a significant negative correlation between birth weight and lead concentrations, but a positive one for zinc and copper, and no significant correlations for mercury. It was reasoned that if lead levels had been raised because some other growth retarding factor had increased the number of metal binding sites in placental tissue as a side effect, raised levels of chemically related elements such as the other plumbing metals, copper and zinc, and mercury, would have been expected too.

Our data may be elucidated further if the two types of neural tube defects are considered separately. The prevalence of anencephaly over the survey period fell significantly in association with increasing hardness of drinking water as mentioned previously, but there was a smaller fall in the prevalence of spina bifida and cranium bifidum. ${ }^{23}$ Other factors such as folic acid deficiency may be more important in the latter group. The MRC trial ${ }^{24}$ showed that folic acid could help to prevent recurrences in mothers who had had one or more previous babies with neural tube defects.

The seasonality of neural tube defects when their prevalence was high in the Fylde was compatible with a role in causation for folate deficiency, particularly in spina bifida and cranium bifidum. Conceptions were more common in December to May for anencephaly, but significantly more common in March to May for spina bifida and cranium bifidum. ${ }^{9}$ These findings may be related to the observation that the lowest folate intake and mean serum folate occurred in March to June in nulliparous women in Dublin. ${ }^{25}$ In another investigation women in early pregnancy in north London ${ }^{26}$ were found to have the lowest means for erythrocyte and serum folate in April to June, but correlation with estimated dietary intake was weak. Sometimes folic acid does not prevent recurrences, and recently an investigation of 16 women who had two infants affected with neural tube defects despite taking vitamin supplements for prevention was reported. ${ }^{27}$ It was suggested that they might have defective folate metabolism. Other possible aetiological factors were not considered.

Lead is a neurotoxin and could cause neural tube defects by direct action on rapidly developing nervous tissue. Alternatively, it could act indirectly by causing zinc deficiency with secondary folate deficiency, a possibility supported by a study of elements in the bones of some stillborn malformed babies. ${ }^{8}$

Lead reduces the bioavailability of zinc from food $^{28}$ and may either cause a deficiency of the element or exacerbate a pre-existing deficiency resulting from a poor dietary intake or malabsorption. An investigation in young women suggested that zinc stores could be easily depleted by a low intake. ${ }^{29}$

Folate uptake is impaired by zinc deficiency. ${ }^{30}$ Dietary folate consists mainly of polyglutamyl folate which is hydrolysed by folate conjugase to monoglutamyl folate before absorption. The enzyme is zinc dependent.

A case-control study of 27 women who were in the MRC trial and had a baby with a neural tube defect showed no association with serum zinc concentrations. ${ }^{31}$ However, plasma or serum zinc levels are an unreliable measure of primary zinc status. ${ }^{32}{ }^{33}$ Leucocyte zinc may be a useful guide, ${ }^{33}$ and a simple zinc taste test has been said to be effective. ${ }^{34}$ The role of zinc 
deficiency in the aetiology of neural tube defects needs further investigation.

Placental studies have provided practical support for a role for lead. In some cases of spina bifida the placenta has shown raised lead and very low zinc contents (D Bryce-Smith, $\mathrm{N}$ I Ward, personal communication).

In conclusion, reasons to believe that lead is one factor in the aetiology of neural tube defects have been given. Calcium and magnesium in hard water are toxicological antagonists of lead. Folate deficiency may follow zinc deficiency, which in turn may be produced or exacerbated by intake of lead. Thus lead could be a common factor linking the known preventive actions of hard drinking water and folic acid.

We thank North West Water and the former Fylde Water Board for providing data on the water supply. We are grateful to Professor D Bryce-Smith for helpful comments.

1 Rogers SC, Weatherall JAC. Anencephalus, spina bifida and congenital hydrocephalus. England and Wales 1964-1972. Office of Population Censuses and Surveys. Studies on Medical and Population Subjects No 32. London: HMSO, 1976.

2 Laurence KM, Carter CO, David PA. Major central nervous system malformations in South Wales. British fournal of system malformations in South Wales. Britis
Preventive and Social Medicine 1967;21:146-60.

3 Savers BMcA, Segal SD, Henshall WR, Bound JP, Harvey Sayers BMcA, Segal SD, Henshall WR, Bound JP, Harvey
PW. Analysis of the occurrence of anencephalic stillbirths PW. Analysis of the occurrence of anencephalic stillbirths in the Fylde

4 Bound JP, Harvey PW, Brookes DM, Sayers BMcA. The incidence of anencephalus in the Fylde peninsula 1956-76 and changes in water hardness. $\mathcal{F}$ Epidemiol Community Health 1981;35:102-5.

5 Lowe CR, Roberts CJ, Lloyd S. Malformations of central nervous system and softness of local water supplies. $B M$ 1971;ii:357-61.

6 Fielding DW, Smithells RW. Anencephalus and water hardness in south-west Lancashire. British fournal of Preventive and Social Medicine 1971;25:217-9.

7 St Leger AS, Elwood PC, Morton MS. Neural tube malformations and trace elements in water. $\mathcal{F}$ Epidemiol Community Health 1980;34:186-7.

8 Bryce-Smith D, Deshpande RR, Hughes J, Waldron HA. Lead and cadmium levels in stillbirths. Lancet 1977;i:1159.

9 Bound JP, Harvey PW, Francis BJ. Seasonal prevalence of major congenital malformations in the Fylde of Lancashire major congenital malformations in the Fylde of Lancashire

10 Kelsey JL, Thompson WD, Evans AS. Methods in observational epidemiology. Oxford: Oxford University Press, 1986

11 Lovett AA, Gatrell AC, Bound JP, Harvey PW, Whelan AR. Congenital malformation in the Fylde region of Lancashire, England 1957-1973. Soc Sci Med 1990;30:103-9.

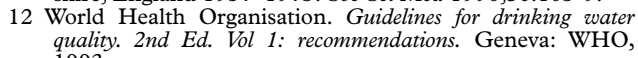
1993.
13 Commission of the European Communities. Proposal for a council directive concerning the quality of water intended for human consumption. Brussels: Commission of the European Communities, 1995

14 Butler NR, Alberman ED, Schutt WH. The congenital malformations. In: Butler NR, Alberman ED eds. Perinatal problems. The second report of the 1958 British Perinatal Mortality Survey. Edinburgh and London: Livingstone, 1969:319.

15 Townsend P, Phillimore P, Beattie A. Health and deprivation: inequality and the north. London: Croom Helm, 1987.

16 Francis B, Green M, Payne C. The GLIM4 system manual. Oxford: Oxford University Press, 1993.

17 Breslow NE, Day NE. Statistical methods in cancer research. Volume 1: the analysis of case-control studies. Lyon: International Agency for Research on Cancer, 1980.

18 Walker A. Drinking water: doubts about quality. BMF 1992; 304:175-7.

19 Jones RR. The continuing hazard of lead in drinking water. Lancet 1989;ii:669-70.

20 Department of the Environment. Lead in drinking water. A survey in Great Britain, 1975-1976. London: HMSO, 1977.

21 Alexander LM, Heaven A, Delves HT, Moreton J. An investigation into lead exposure in children living in the Blackpool, Wyre and Fylde Health Authority. Lancaster: Lancaster University, 1993.

22 Ward NI, Durrant S, Sankey RJ, Bound JP, Bryce-Smith D. Elemental factors in human fetal development. fournal of Nutritional Medicine 1990;1:19-26.

23 Bound JP, Francis BJ, Harvey PW. Neural tube defects, maternal cohorts, and age: a pointer to aetiology. Arch Dis Child 1991;66:1223-6.

24 MRC Vitamin Study Research Group. Prevention of neural tube defects: results of the MRC vitamin study. Lancet 1991;338:131-7.

25 Wickham C, O'Broin S, Kevany J. Seasonal variation in folate nutritional status. Ir f Med Sci 1983;152:295-9.

26 Leck I, Iles CA, Sharman IM, Toe T, Wadsworth GR. Maternal diet and nutrition during early pregnancy and after delivery in North London. In: Dobbing J, ed. Prevention of spina bifida and other neural tube defects. London: Academic Press, 1983:197-218.

27 Wild J, Seller MJ, Schorah CJ, Smithells RW. Investigation of folate intake and metabolism in women who have had two pregnancies complicated by neural tube defects. $\mathrm{Br} \mathcal{F}$ Obstet Gynaecol 1994;101:197-202.

28 Jameson S. Zinc status in pregnancy: the effect of zinc therapy on perinatal mortality, prematurity, and placental ablation. Ann N Y Acad Sci 1993;678:178-92.

29 Hess FM, King JC, Margen S. Effect of low zinc intake and oral contraceptive agents on nitrogen utilization and clinical findings in young women. $\mathcal{F}$ Nutr 1977 ; 107:221927.

30 Tamura T, Shane B, Baer MT, King JC, Margen S, Stokstad ELR. Absorption of mono and polyglutamyl folates in zinc-depleted man. Am f Clin Nutr 1978;31:1984-7.

31 Hambridge $M$, Hackshaw A, Wald N. Neural tube defects and serum zinc. Br f Obstet Gynaecol 1993;100:746-9.

32 Bryce-Smith D, Ward NI. Nutrition and pre-conception care. Lancet 1985;ii:1297-8.

33 Keeling PWN, Jones RB, Hilton PJ, Thompson RPH. Reduced leucocyte zinc in liver disease. Gut 1980;21:5614.

34 Bryce-Smith D, Simpson RID. Anorexia, depression, and zinc deficiency. Lancet 1984;ii: 1162 . 